\title{
Genetic parameter estimates for important traits on the fifth generation in red tilapia in Vietnam
}

\author{
Sang V. Nguyen*, Phuc H. Tran, Truong V. Dang, \& Khoa D. Pham \\ Research Institute for Aquaculture No. 2, Ho Chi Minh City, Vietnam
}

\begin{abstract}
ARTICLE INFO
Research Paper

Received: January 21, 2021

Revised: February 18, 2021

Accepted: February 26, 2021

\section{Keywords}

Body colour

Genetic parameters

Growth

Red tilapia

Survival

\section{${ }^{*}$ Corresponding author}

Nguyen Van Sang

Email: nvsangumb@gmail.com

ABSTRACT

Genetic parameters comprising heritability, genetic correlation and genotype by environment interaction $(\mathrm{GxE})$ for growth survival rate and body colour at harvest were estimated on the $5^{\text {th }}$ selective generation of red tilapia grown in two environments, freshwater and brackishwater ponds. A total of 116 full- half-sib families was produced as well as 4,432 and 3,811 tagged individuals were tested in freshwater and brackishwater ponds, respectively. Genetic parameters were estimated by ASReml 4.1 software. The heritability for body weight and survival rate was high while medium heritability for body colour in freshwater was observed. The heritability for those traits of red tilapia in brackishwater. Together with the figures in earlier publication on previous generations (G1 to G4) in the same selective population, the expected medium to high response acquires if selection is done for each trait. Genetic correlations among harvest body weight, survival rate and body colour are insignificantly different and ranging from -0.25 to $0.37(P>0.05)$. These results implied that selection on one trait do not influence on responses of the other traits. GxE interaction for body weight and body colour between two tested environments is mostly negligible with genetic correlations ranging from $0.63-0.80$ while it is important for survival trait $\left(\mathrm{r}_{\mathrm{g}}=\right.$ $-0.17 \pm 0.40)$.

Cited as: Nguyen, S. V., Tran, P. H., Dang, T. V., \& Pham, K. D. (2021). Genetic parameter estimates for important traits on the fifth generation in red tilapia in Vietnam. The Journal of Agriculture and Development 20(1), 49-57.
\end{abstract}




\title{
Ước tính các thông số di truyền một số tính trạng quan trọng trên quần thể chọn giống rô phi đỏ thế hệ thứ 5 tại Việt Nam
}

\author{
Nguyễn Văn Sáng*, Trần Hữu Phúc, Đặng Văn Trường \& Phạm Đăng Khoa \\ Viện Nghiên Cứu Nuôi Trồng Thủy Sản II, TP. Hồ Chí Minh
}

\author{
THÔNG TIN BÀI BÁO \\ Bài báo khoa học \\ Ngày nhận: 21/01/2021 \\ Ngày chỉnh sưa: 18/02/2021 \\ Ngày chấp nhận: 26/02/2021 \\ Từ khóa \\ Màu sắc \\ Rô phi đỏ \\ Tăng trưởng \\ Thông số di truyền \\ Tỷ lệ sống \\ *Tác giả liên hệ \\ Nguyễn Văn Sáng \\ Email: nvsangumb@gmail.com
}

\section{TÓM TẮT}

Nghiên cứu thực hiện ước tính các thông số di truyền bao gồm hệ số di truyền, tương quan di truyền và tương tác giữa kiểu gen và môi trường (GxE) các tính trạng tăng trưởng, tỷ lệ sống và màu sắc rô phi đỏ chọn giống thế hệ thứ năm sau khi nuôi ở ao nước ngọt và lợ mặn. Tổng cộng có 116 gia đình full- và half-sib được tạo ra, 4.432 và 3.811 cá giống được đánh dấu từng cá thể và thả nuôi đánh giá các tính trạng tương ứng trong ao nước ngọt và ao lợ mặn. Các thông số di truyền được ước tính bằng phần mềm ASReml 4.1. Hệ số di truyền đạt mức cao cho tính trạng khối lượng $(0,42)$, tỷ lệ sống $(0,58)$ và mức trung bình cho màu sắc $(0,23)$ nuôi ở môi trường nước ngọt, trong khi đó 3 tính trạng tương ứng ở môi trường nước lợ là 0,$26 ; 0,26$ và 0,29 . Kết quả này cùng với các giá trị công bố ở các thế hệ trước cho thấy tiềm năng chọn lọc mang lại hiệu quả từ trung bình đến cao cho từng tính trạng. Tương quan di truyền khác zero (0) không có ý nghĩa thống kê $(P>0,05)$ được tìm thấy giữa ba tính trạng (từ $-0,25$ đến 0,37 ) cho thấy chọn lọc nâng cao một trong ba tính trạng sẽ không ảnh hưởng đến hiệu quả của tính trạng còn lại. Tương tác GxE cho các tính trạng tăng trưởng và màu sắc giữa hai môi trường nước ngọt và lợ mặn là không đáng kể (với hệ số tương quan 0,63 - 0,80), nhưng tương tác đáng kể cho tính trạng tỷ lệ sống giữa hai môi trường nuôi được tìm thấy $\left(\mathrm{r}_{\mathrm{g}}=-0,17 \pm 0,40\right)$.

\section{1. Đặt Vấn Đề}

Cá rô phi đỏ và vằn là 2 đối tượng nuôi nước ngọt chủ lực sau cá tra với sản lượng năm 2020 đạt 260.000 tấn (Nguyen, 2021). Cá rô phi đỏ hiện được nuôi tập trung chủ yếu ở Nam Bộ. Tuy nhiền, nghề nuôi cá rô phi đỏ hiện còn nhiều hạn chế về chất lượng con giống. Thứ nhất, tăng trưởng kém, cá rô phi đỏ nuôi bè hoặc nuôi đăng quần sau 6 tháng chỉ mới đạt trung bình 500 $\mathrm{g} /$ con, chỉ bằng $80 \%$ so với cá rô phi vằn dòng GIFT, do đó hiệu quả kinh tế chưa cao. Thứ hai, sức sống thấp, con giống dễ bệnh, tỷ lệ hao hụt cao (tỷ lệ chết là $35 \%$ vào năm 2014 ) và có thời điểm tỷ lệ hao hụt lên tới $70 \%$ từ giai đoạn cá giống đến khi thu hoạch, làm tăng chi phí sản xuất, nghề nuôi đạt hiệu quả kém (Trinh \& ctv., 2016). Thứ ba, cá rô phi đỏ hiện nay có màu sắc không thuần nhất, đôi khi lẫn nhiều đốm đen, chưa phù hợp thị hiếu người tiêu dùng. Thị trường luôn ưa chuộng và trả giá cao hơn cho những cá thể có màu hồng phấn hoàn toàn, không lẫn đốm đen.

Cá rô phi đỏ chọn giống tại Viện Nghiên cứu Nuôi trồng Thủy sản II (Viện 2) có nguồn gốc từ các dòng cá Ecuador, Đài Loan, Malaysia và Thái Lan. Chương trình chọn giống cá rô phi đỏ tại Viện 2 dựa trên lý thuyết di truyền số lượng đã được chứng minh là cách thức khoa học và có hiệu quả nhằm nâng cao các tính trạng mong muốn. Hệ số di truyền ước tính cho tính trạng tăng trưởng dao động từ mức trung bình đến cao qua các thế hệ chọn giống thứ 1 đến thứ 4 (G1 - G4) là 0,19 - 0,35 và cho tính trạng màu sắc (theo 3 mức đốm đen: không đốm, đốm ít, đốm nhiều) ở mức trung bình đến cao $(0,27-0,33)$ khi nuôi ở môi trường nước ngọt. Trong môi trường nuôi nước mặn, hệ số di truyền ước tính đạt mức trung bình cho tính trạng tăng trưởng 0,26 - 0,28 (G1-G2) và về màu sắc ở mức trung bình đến cao $(0,30$ ở $\mathrm{G} 1$ và 0,24 ở $\mathrm{G} 2)$. Kết quả đánh giá tương tác kiểu gen và môi trường $(\mathrm{GxE})$ của cả 
hai tính trạng (tăng trưởng và màu sắc) thông qua hệ số tương quan của cùng tính trạng đánh giá ở 2 môi trường nuôi nước ngọt và lợ mặn ở mức 0,67-0,85 tức tương tác yếu (G1 - G2) cho tăng trưởng (Trinh \& ctv., 2016). Mục tiêu của nghiên cứu này là đánh giá tính ổn định của hệ số di truyền, khẳng định tương tác $\mathrm{GxE}$ cho hai tính trạng tăng trưởng và màu sắc, khả năng di truyền tính trạng mới quan tâm là tỷ lệ sống nuôi ở cả 2 môi trường nước ngọt và lợ mặn thực hiện trên quần thể chọn giống thế hệ thứ 5 , phục vụ cho định hướng chọn lọc lâu dài và cung cấp giống phục vụ sản xuất tại Việt Nam.

\section{Vật Liệu và Phương Pháp Nghiên Cứu}

2.1. Nuôi vỗ bố mẹ G4, ghép cặp cho sinh sản, ấp và ương riềng rẽ đến kích cỡ đánh dấu

Cá bố mẹ đã chọn lọc tăng trưởng nhanh thế hệ G4 được nuôi vỗ theo qui trình sản xuất giống cá rô phi đỏ được hoàn thiện tại Viện 2 (Trinh \& ctv., 2016). Khi tỷ lệ cá cái sẵn sàng đẻ là $64,3 \%$, tỷ lệ cá đực sẵn sàng đẻ là $100 \%$ và khối lượng trung bình tương ứng là $499 \mathrm{~g}$ và $816 \mathrm{~g}$ thì tiến hành cho sinh sản. Kỹ thuật lựa chọn cá đực, cá cái thành thục và phương pháp ghép cặp để sản xuất gia đình full- và half-sib dựa theo phương pháp sản xuất giống trong chương trình chọn giống rô phi dòng GIFT (WFC, 2004). Kết quả sau 29 ngày ghép cặp (từ ngày $4 / 1-2 / 2 / 2018$ ) đã thu được 196 gia đình cá rô phi đỏ G5 (thế hệ thứ 5) theo 7 đợt sinh sản từ 116 cá mẹ và 63 cá bố. Trong đó, có 10 gia đình cùng cha cùng mẹ (full-sib) và không có cùng cha khác mẹ (half-sib) và 53 gia đình cá cùng cha khác mẹ thứ 2 (half-sib 2).

Trứng thụ tinh được thu, ấp nở và ương riêng rẽ theo gia đình đến kích cỡ đánh dấu. Sau thời gian ương trung bình là 105 ngày (dao động trong khoảng 74 đến 130 ngày), cá giống có kích cỡ trung bình $7,9 \mathrm{~g}$ theo khối lượng $( \pm \mathrm{SD}= \pm$ $3,6), 7,6 \mathrm{~cm}$ chiều dài tổng $( \pm 1,2), 6,0 \mathrm{~cm}$ chiều dài chuẩn $( \pm 1,3)$ và $2,3 \mathrm{~cm}$ chiều cao thân $( \pm$ $0,6)$ được đánh dấu từ PIT (Passive Integrated Transponder) theo từng cá thể.

\section{2. Đánh dấu, nuôi đánh giá các tính trạng ở} hai môi trường nuôi nước ngọt và lợ mặn

Đối với các gia đình có số lượng cá thể đạt kích cỡ cá giống nhỏ hơn 60 con thì đánh dấu PIT hết số lượng và số gia đình còn lại đánh dấu 60 con/gia đình. Thả nuôi đánh giá tăng trưởng ao nuôi nước ngọt 4.432 cá thể đã đánh dấu PIT tại Trung tâm Quốc gia Giống Thủy sản Nước ngọt Nam Bộ, Tiền Giang trong một ao $2.000 \mathrm{~m}^{2}$, độ sâu nước $1,5 \mathrm{~m}$ và 3.811 cá thể trong ao nước lợ mặn tại Trại Thực nghiệm Thủy sản nước lợ Nam Sông Hậu, Bạc Liêu trong một ao $2.000 \mathrm{~m}^{2}$, dộ sâu nước 1,5 m. Độ mặn nước trong ao nuôi lợ mặn trung bình $17,4 \%$, cao nhất $22,5 \%$ ovà thấp nhất 12,0\%o. Cho cá ăn 3 - 5\% khối lượng thân bằng thức ăn viên công nghiệp ở nhiều vị trí khác nhau trong ao nuôi để giảm thiểu khả năng ảnh hưởng của thức ăn lên các tính trạng khảo sát. Sục khí liên tục trong ao nuôi. Sử dụng định kỳ chế phẩm vi sinh nhằm cải thiện chất lượng nước ao nuôi. Thay nước 2 lần/tháng và thay liên tục hàng ngày trong thời gian triều cường, mỗi lần thay $30 \%$ thể tích nước ao. Theo dõi các chỉ tiêu thủy lý hóa nước ao nuôi như oxy hòa tan, $\mathrm{pH}$ và nhiệt độ. Khi cá hết thời gian nuôi tăng trưởng, phân biệt được cá đực và cá cái, tiến hành thu thập số liệu cho tính trạng tăng trưởng, màu sắc và tỷ lệ sống.

\subsection{Thu thập và xử lý số liệu}

\subsubsection{Thu thập số liệu}

Sau gần 6 tháng (162 - 175 ngày) nuôi trong ao nước ngọt và hơn 5 tháng (156 - 162 ngày) nuôi trong ao nước lợ mặn tiến hành thu hoạch thu thập số liệu. Cá được gây mê bằng ethylene glycol monophenyl ether nồng độ $0,25 \mathrm{ppm}$. Từng cá thể được truy dấu từ PIT; ghi nhận giới tính (đực, cái); chiều dài tổng, chiều dài chuẩn, chiều cao thân, chiều rộng (dầy thân) được đo bằng thước và thước kẹp đến $1 \mathrm{~mm}$; khối lượng được cân đến $0,1 \mathrm{~g}$; tỷ lệ sống được ghi nhận tương ứng là "0" và " "l" nếu cá thể đó đã chết và còn sống lúc thu hoạch; màu sắc được đánh giá bằng mắt thường sự hiện diện của đốm đen trên bề mặt cơ thể, được ghi nhận theo ba mức độ là (1) "không đốm", (2) "ít đốm" ( $<5 \%$ diện tích bề mặt cơ thể) và (3) "nhiều đốm" (> $>5 \%$ diện tích bề mặt cơ thể). Tính trạng màu sắc được chia làm 2 nhóm là 'đạt' (không đốm và ít đốm) và 'không đạt' (nhiều đốm).

\subsubsection{Xử lý số liệu}

\section{Phương sai thành phần và hệ số di truyền các tính trạng khảo sát}

Số liệu được lưu giữ và kiểm tra bằng phần 
mềm Microsoft@ Excel 2010. Mô tả thống kê bằng phần mềm $\mathrm{R}$ (V 3.4.4). Mô hình tuyến tính hỗn hợp cá thể (animal linear mixed model) (Mô hình 1) được dùng để ước tính các thành phần phương sai bằng phần mềm $\mathrm{ASReml}$ phiên bản 4.1 (Gilmour \& ctv., 2015) và từ đó ước tính các thông số di truyền của tính trạng tăng trưởng (chiều dài, khối lượng lúc thu hoạch):

Tăng trưởng $\mathrm{ijkl}_{\mathrm{i} k}=\mu+\beta_{1} \times$ tuổi cá $_{\mathrm{i}}+\beta_{2} \times$ $(\text { tuổi cá })_{\mathrm{i}}^{2}+$ giới tính $\mathrm{j}+$ cá thể $\hat{\mathrm{k}}_{\mathrm{k}}+$ cá mẹ ${ }_{1}+\mathrm{e}_{\mathrm{ijkl}}$ (1).

Trong đó:

Tăng trưởng $g_{i j k l}$ là tăng trưởng khi thu hoạch của cá thể $\mathrm{k}$.

$\mu$ là giá trị trung bình của quần thể.

$\beta_{1}$ là hệ số hồi quy của hiệp biến 'tuổi cá'.

tuổi cái là ảnh hưởng cố định của tuổi i của từng cá thể tính từ ngày cá được đẻ ra đến ngày thu hoạch lên tăng trưởng.

$\beta_{2}$ là hệ số hồi quy bậc hai (quadratic regression) của hiệp biến bình phương tuổi cá '(thời gian nuôi $)^{2}$.

(tuổi cá) $)_{i}^{2}$ là ảnh hưởng cố định bậc hai của tuổi i của từng cá thể tính từ ngày cá được đẻ ra dến ngày thu hoạch lên tăng trưởng.

giới tính $\mathrm{j}_{\mathrm{j}}$ là ảnh hưởng cố định của giới tính $\mathrm{j}$ (đực hoặc cái) lên tăng trưởng.

cá thể là ảnh hưởng di truyền cộng gộp của cá thể $\mathrm{k}$.

cá mẹ là ảnh hưởng của môi trường chung (environmental effect common to full-sibs, $c^{2}$ ) của các cá con của cùng một cá mẹ l.

$\mathrm{e}_{\mathrm{ijkl}}$ là ảnh hưởng của số dư.

Đối với tính trạng nhị phân màu sắc ("đạt"/"không đạt") và tỷ lệ sống ("sống"/"chết"), phương trình tuyến tính cá thể hỗn hợp sử dụng hàm logit (logit link function, phần mềm tự chuyển số liệu sang dạng logarit trước khi phân tích), với ảnh hưởng cố định là 'giới tính', 'tuổi cá', 'tuổi đánh dấu' và ảnh hưởng ngẫu nhiên là 'cá thể'. 'Tuổi đánh dấu' là ảnh hưởng cố định của tuổi của từng cá thể tính từ ngày cá được đẻ ra đến ngày đánh dấu từ PIT.

Màu sắc $\mathrm{ijk}_{\mathrm{jk}}=\mu+\beta_{1} \times$ tuổi cái $+\beta_{2} \times$ (tuổi cá $)_{\mathrm{i}}^{2}+$ giới tính $_{\mathrm{j}}+$ cá thể ${ }_{\mathrm{k}}+\mathrm{e}_{\mathrm{ijkl}}(2)$.

Tỷ lệ sống ij $_{i j}=\mu+\beta_{1} \times$ tuổi đánh dấu $u_{i}+$ cá thể $\mathrm{e}_{\mathrm{j}}+\mathrm{e}_{\mathrm{ij}}(3)$.

Các thành phần phương sai bao gồm $\delta_{\mathrm{a}}^{2}$ là phương sai di truyền cộng gộp, $\delta_{\mathrm{c}}^{2}$ là phương sai ảnh hưởng môi trường ương riêng rẽ đến kích cỡ đánh dấu, $\delta_{\mathrm{e}}^{2}$ là phương sai số dư và $\delta_{\mathrm{P}}^{2}$ là phương sai kiểu hình được ước tính bằng các mô hình nếu trên. Hệ số di truyền (heritability, $\mathrm{h}^{2}$ ) được định nghĩa là tỉ số giữa phương sai của giá trị di truyền cộng gộp (additive genetic variance, $\sigma_{\mathrm{A}}^{2}$ ) và phương sai kiểu hình đo đạc được của tính trạng chọn lọc (phenotypic variance, $\sigma_{\mathrm{P}}^{2}$ ). Tính trạng có hệ số di truyền cao đồng nghĩa với việc kiểu hình được đo đạc ước đoán tốt cho kiểu gen của tính trạng đó và ngược lại.

Đối với tính trạng tăng trưởng (chiều dài, khối lượng lúc thu hoạch), hệ số di truyền $\left(\mathrm{h}^{2}\right)$ được tính theo công thức $\mathrm{h}^{2}=\frac{\sigma_{\mathrm{A}}^{2}}{\sigma_{\mathrm{A}}^{2}+\sigma_{\mathrm{C}}^{2}+\sigma_{\mathrm{E}}^{2}}(4)$.

Đối với tính trạng màu sắc $\frac{\sigma_{\mathrm{A}}^{2}}{\sigma_{\mathrm{A}}^{2}+\sigma_{\mathrm{E}}^{2}}(5)$, không bao gồm ảnh hưởng c $c^{2}$.

$$
\text { Tỷ lệ sống } \mathrm{h}^{2}=\frac{\sigma_{\mathrm{A}}^{2}}{\sigma_{\mathrm{A}}^{2}+\sigma_{\mathrm{E}}^{2} \times \frac{\pi^{2}}{3}} \text { (6) do không }
$$

bao gồm ảnh hưởng $\mathrm{c}^{2}$ (vì mô hình toán không hội tụ được) và khi sử dụng hàm logit thì $\sigma_{\mathrm{E}}^{2}$ được cố định bằng 1 .

Ảnh hưởng $\mathrm{c}^{2}$ của môi trường ương nuôi riêng rẽ của tính trạng tăng trưởng (chiều dài, khối lượng lúc thu hoạch) được tính theo công thức $\mathrm{c}^{2}$ $=\frac{\sigma_{\mathrm{C}}^{2}}{\sigma_{\mathrm{A}}^{2}+\sigma_{\mathrm{C}}^{2}+\sigma_{\mathrm{E}}^{2}}(7)$.

\section{Tương tác kiểu gen - môi trường (tương} tác $\mathbf{G} \times \mathbf{E}$ )

Tương tác $\mathrm{G} \times \mathrm{E}$ của quần thể $\mathrm{G} 5$ nuôi trong hai môi trường nước ngọt và lợ mặn được đánh giá thông qua tương quan di truyền $\left(\mathrm{r}_{\mathrm{g}}\right)$ của tính trạng (chiều dài, khối lượng, màu sắc và tỷ lệ sống) khi thu hoạch giữa hai môi trường và tương quan di truyền được tính theo công thức: $\mathrm{r}_{\mathrm{g}}=$ $\frac{\sigma_{12}}{\sqrt{\sigma_{1}^{2}}+\sqrt{\sigma_{2}^{2}}}(8)$

Trong đó $\sigma_{12}$ là hiệp phương sai của ảnh hưởng di truyền cộng gộp của khối lượng thu hoạch trong hai môi trường nuôi, $\sigma_{1}^{2}$ và $\sigma_{2}^{2}$ lần lượt là phương sai của ảnh hưởng di truyền cộng gộp của tính trạng (chiều dài, khối lượng, màu sắc và tỷ lệ sống) thu hoạch trong môi trường nước ngọt và môi trường nước lợ mặn và được ước tính bằng mô hình hai biến với các biến cố định và ngẫu nhiên tương tự như mô tả trong mô hình (1), (2) và (3) tương ứng cho từng tính trạng thu hoạch (chiều dài, khối lượng, màu sắc và tỷ lệ sống). 
Tương quan di truyền có thể được tính toán bằng phần mềm ASReml 4.1 (Gilmour \& ctv., 2015).

Tương quan di truyền (genetic correlation, $r_{\mathrm{g}}$ ) giữa các tính trạng khảo sát

Tương quan di truyền (genetic correlation, $\mathrm{r}_{\mathrm{g}}$ ) cho biết mối tương quan di truyền của hai tính trạng quan tâm bao gồm chiều dài, khối lượng, màu sắc và tỷ lệ sống trong từng môi trường nuôi.

\section{Kết Quả và Thảo Luận}

\subsection{Giá trị kiểu hình các tính trạng nghiên cứu}

Khi thu hoạch số lượng các cá thể còn sống thuộc đầy đủ 116 gia đình còn cho 2 môi trường nuôi. Số lượng, khối lượng trung bình và tỷ lệ sống trung bình tương ứng cho 2 môi trường nước ngọt và lợ mặn là 3.470 cá thể, $473,3 \mathrm{~g}, 78,3 \%$ và 3.231 cá thể, $434,4 \mathrm{~g}$ và $84,9 \%$. Chiều dài tổng và chuẩn trung bình tương ứng cho 2 môi trường nước ngọt và lợ mặn là $27,7 \mathrm{~cm}$ và $22,8 \mathrm{~cm}, 27,3 \mathrm{~cm}$ và 22,5 cm (Bảng 1). Nhìn chung, các chỉ tiêu tính trạng tăng trưởng khi cá nuôi nước ngọt bao gồm khối lượng, chiều dài tổng, chiều dài chuẩn là cao hơn so với cá nuôi nước lợ mặn. Tỷ lệ sống của G5 - nước ngọt $(78,3 \%)$ thấp hơn tỷ lệ sống của G5 - lợ mặn $(84,9 \%)$ kết quả này phù hợp với báo cáo trền cùng quần thể chọn giống nhưng ở thế hệ trước, G1 - nước ngọt (65,0\%) và G1 - lợ mặn $(66,7 \%)$ là cá nuôi trong môi trường nước mặn có tỷ lệ sống cao hơn nuôi trong môi trường nước ngọt (Trinh \& ctv., 2013). Tỷ lệ cá có màu sắc "đạt" và màu sắc "không đạt" tương ứng cho 2 môi trường nước ngọt và lợ mặn là 99,0\%, 1,0\% và $82,0 \%, 16,0 \%$.

Hệ số biến thiên $(\mathrm{CV}, \%)$ là một đại lượng quan trọng dùng để nghiên cứu mức độ biến dị và đặc biệt khi cần so sánh mức độ biến dị của tính trạng giữa các nhóm, các quần thể hay các loài khác nhau hoặc giữa các tính trạng khác nhau trong cùng một loài (Tran \& Dang, 2005). Trong nghiên cứu này, giá trị $\mathrm{CV}$ của khối lượng thu hoạch cao ở cả hai môi trường ao nuôi nước ngọt và nước lợ mặn lần lượt $25,7 \%$ và $29,1 \%$. Tỷ lệ sống có giá trị CV cao ở ao nuôi nước ngọt 32,6\%, trong khi các tính trạng tăng trưởng khác và tỷ lệ sống của ao nuôi nước lợ mặn có giá trị CV thấp hơn $(8,8$ - 12,2\%). Hệ số biến thiên của tính trạng khối lượng nằm trong khoảng báo cáo cá rô phi đỏ các thế hệ G2, G3, G4 (dao động 21,7 - 30,1\%; Trinh \& ctv., 2017). Hệ số biến thiên tính trạng chiều dài tổng và chiều dài chuẩn thấp nhất ở cả hai môi trường nuôi $(9,0-9,5 \%)$ và $8,8-9,8 \%)$.

\subsection{Hệ số di truyền các tính trạng nghiên cứu}

Các thành phần phương sai và hệ số di truyền của tính trạng tăng trưởng (thông qua khối lượng), màu sắc và tỷ lệ sống tại thời điểm thu hoạch của thế hệ G5 được trình bày tại Bảng 2 . Hệ số di truyền ước tính $\left(\mathrm{h}^{2}\right)$ của khối lượng thu hoạch đạt ở mức cao $(0,42)$ ở nước ngọt và trung bình $(0,26)$ ở nước lợ mặn, khác biệt có ý nghĩa thống kê so với 0 (zero). Hệ số di truyền cho khối lượng lúc thu hoạch ở nghiên cứu này trên thế hệ G5 ở nước ngọt cao hơn ở các thế hệ trước (G1: 0,$35 ; G 2: 0,22 ; G 3: 0,19$ và $G 4: 0,29)$ và ở nước lợ mặn là tương đương với các thế hệ trước (G1: 0,28; G2: 0,33) (Trinh \& ctv., 2013; Trinh \& ctv., 2017). Với hệ số di truyền cho tính trạng khối lượng lúc thu hoạch ở mức trung bình và cao qua các thế hệ từ 1 đến 5 cho thấy tiềm năng cải thiện di truyền sẽ ở mức trung bình và cao nếu chúng ta cho chọn lọc cho tính trạng này. Ảnh hưởng của môi trường ương nuôi riêng rẽ $\left(c^{2}\right)$ lên khối lượng lúc thu hoạch ở cả 2 môi trường ở mức thấp và khác biệt không có ý nghĩa so với zero $(0,05 \pm 0,03$ và $0,05 \pm 0,03)$. Giá trị c $c^{2}$ ở mức cao hơn và khác zero có ý nghĩa thống kê được công bố ở các thế hệ trước G1 - G4 trên cùng quần thể chọn giống $(0,07-0,17$; Trinh \& ctv., 2013; Trinh \& ctv., 2017). Theo Bentsen \& ctv. (2012), ảnh hưởng của môi trường $\mathrm{c}^{2}$ trên cá rô phi vằn dao động trong khoảng $0,08-0,21$. Do đó, đối với quần thể G5 thì ảnh hưởng $\mathrm{c}^{2}$ được cải thiện nhờ thời gian sinh sản các gia đình, thời gian ương các gia đình được rút ngắn nên giảm thiểu ảnh hưởng $\mathrm{c}^{2}$.

Hệ số di truyền ước tính $\left(\mathrm{h}^{2}\right)$ trên tính trạng màu sắc ở mức trung bình $(0,23)$ và $(0,29)$ ở nước ngọt và lợ mặn và khác biệt có ý nghĩa thống kê so với 0 (zero). Hệ số di truyền này nằm trong khoảng công bố trên cùng quần thể chọn giống nhưng ở thế hệ trước ở nước ngọt G2-G4 (dao động 0,27 - 0,33) và nước lợ mặn G1 - G2 (0,24 $0,31)$. Với hệ số di truyền cho tính trạng màu sắc lúc thu hoạch ở mức trung bình và cao qua các thế hệ từ 2 đến 5 cho thấy tiềm năng hiệu quả mang lại sẽ ở mức trung bình và cao nếu chúng ta chọn lọc cho tính trạng này. Thêm vào đó, hệ số di truyền cao cũng được công bố trên quần thể chọn giống cá rô phi đỏ Progift tại Trung Quốc $(0,51)$ (Thodesen \& ctv., 2013) càng hỗ trợ cho nhận định trên. Hệ số di truyền ước tính $\left(\mathrm{h}^{2}\right)$ 
Bảng 1. Giá trị kiểu hình các tính trạng kháo sát tại thời điểm thu hoạch ở hai môi trường nuôi

\begin{tabular}{|c|c|c|c|c|}
\hline Môi trường nuôi & Tính trạng & Đơn vị & $\begin{array}{l}\text { Trung bình } \pm \text { Độ } \\
\text { lệch chuẩn SD }\end{array}$ & Hệ số biến thiên CV (\%) \\
\hline \multirow{7}{*}{ Nước ngọt } & Khối lượng & $\mathrm{g}$ & $473,3 \pm 121,9$ & 25,7 \\
\hline & Chiều dài tổng & $\mathrm{cm}$ & $27,7 \pm 2,5$ & 9,0 \\
\hline & Chiều dài chuẩn & $\mathrm{cm}$ & $22,8 \pm 2,0$ & 8,8 \\
\hline & Tỷ lệ sống & $\%$ & $78,3 \pm 25,5$ & 32,6 \\
\hline & Màu sắc & & & \\
\hline & Ủa chuộng & $\%$ & 99,0 & \\
\hline & Không & $\%$ & 1,0 & \\
\hline \multirow{7}{*}{ Nước lợ mặn } & Khối lượng & $\mathrm{g}$ & $434,4 \pm 126,4$ & 29,1 \\
\hline & Chiều dài tổng & $\mathrm{cm}$ & $27,3 \pm 2,6$ & 9,5 \\
\hline & Chiều dài chuẩn & $\mathrm{cm}$ & $22,5 \pm 2,2$ & 9,8 \\
\hline & Tỷ lệ sống & $\%$ & $84,9 \pm 8,4$ & 9,9 \\
\hline & Màu sắc & & & \\
\hline & Uaa chuộng & $\%$ & 82,0 & \\
\hline & Không & $\%$ & 18,0 & \\
\hline
\end{tabular}

Bảng 2. Các thành phần phương sai, hệ số di truyền và ảnh hưởng của môi trường ương riêng rẽ các tính trạng kháo sát tại thời điểm thu hoạch ở hai môi trường nuôi

\begin{tabular}{lcccccc}
\hline Tính trạng & $\sigma_{\mathrm{A}}^{2}$ & $\sigma_{\mathrm{C}}^{2}$ & $\sigma_{\mathrm{E}}^{2}$ & $\sigma_{\mathrm{P}}^{2}$ & $\mathrm{~h}^{2} \pm \mathrm{SE}$ & $\mathrm{c}^{2} \pm \mathrm{SE}$ \\
\hline Nước ngọt & & & & & & \\
Tăng trưởng & 1235,7 & 987,6 & 6701,6 & 8924,9 & $0,42 \pm 0,12$ & $0,05 \pm 0,05$ \\
Tỷ lệ sống & 0,2 & - & 0,07 & 0,3 & $0,58 \pm 0,06$ & - \\
Màu sắc & 144,2 & - & 456,4 & 600,6 & $0,23 \pm 0,05$ & - \\
Lợ mặn & & & & & & \\
Tăng trưởng & 867,7 & $1.067,9$ & $9.350,2$ & $11.286,0$ & $0,26 \pm 0,09$ & $0,05 \pm 0,03$ \\
Tỷ lệ sống & 0,0009 & - & 0,1 & 0,1 & $0,26 \pm 0,04$ & - \\
Màu sắc & 488,2 & - & 986,8 & 1475,0 & $0,29 \pm 0,05$ & - \\
\hline
\end{tabular}

trên tính trạng tỷ lệ sống đạt ở mức cao ở môi trường nước ngọt $(0,58)$ và ở mức trung bình ở môi trường nước lợ mặn $(0,26)$ và khác biệt có ý nghĩa thống kê so với 0 (zero). Chưa có công bố hệ số di truyền tính trạng tỷ lệ sống trên cá rô phi đỏ ở các thế hệ chọn giống trước, nhưng ở cá tra và tôm sú thì hệ số di truyền này tương ứng cũng ở mức trung bình $(0,27$; Nguyen \& ctv., 2019) và mức cao $(0,34$ - 0,45; Nguyen \& ctv., 2020). Tính trạng tỷ lệ sống rất quan trọng quyết định đến hiệu quả của nghề nuôi, nên với hệ số di truyền trung bình và cao ở quần thể rô phi đỏ chọn giống G5 cho thấy tiềm nay chọn lọc mang lại hiệu quả của tính trạng này.

\subsection{Tương quan di truyền giữa các tính trạng nghiên cứu}

Bảng 3 thể hiện tương quan di truyền và kiểu hình các tính trạng tăng trưởng, màu sắc và tỷ lệ sống nghiên cứu trong môi trường ao nuôi nước ngọt và lợ mặn trên quần thể chọn giống thế hệ G5. Tương quan di truyền thuận và gần như tuyệt đối giữa chiều dài tổng và chuẩn $(0,98-0,99)$, cho thấy chúng ta có thể chọn một trong hai chỉ tiêu trong tương lai cho ước tính các thông số di truyền và chọn lọc. Tương quan di truyền thuận và cao được tìm thấy giữa tính trạng khối lượng với chiều dài tổng và chiều dài chuẩn ở cả 2 môi trường nuôi $(0,83$ - 0,86), cho phép nhận định nếu chúng ta chọn lọc nâng cao khối lượng thì cũng nâng cao chiều dài tương ứng hay nói cách khác không làm thay đổi hình dạng của cá. Tương quan di truyền thuận hay nghịch thấp được tìm thấy giữa tính trạng khối lượng với tính trạng tỷ lệ sống ở 2 môi trường nuôi $(0,25$ và 0,27$)$ và với màu sắc $(-0,08$ và 0,16$)$ và tương quan này khác zero không có ý nghĩa thống kê $(P>0,05)$. Tương quan di truyền nghịch và thấp $(-0,25$ và - 0,22$)$ được tìm thấy giữa các tính trạng màu sắc và tỷ lệ sống tương ứng 2 môi trường nuôi và 


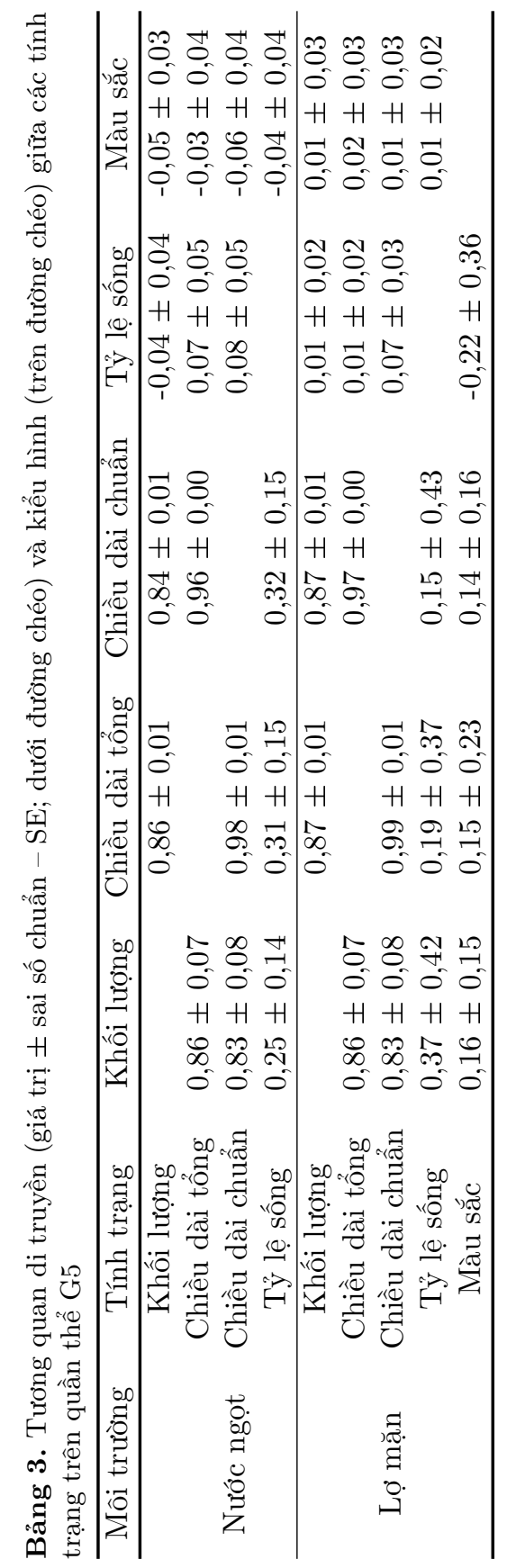

tương quan này khác zero không có ý nghĩa thống kê. Kết quả này cho thấy nếu chọn lọc nâng cao khối lượng hay 1 trong 2 tính trạng kia thì không làm thay đổi lớn cải thiện di truyền 2 tính trạng còn lại. Đây được xem là kết quả công bố đầu tiên về tương quan giữa tăng trưởng với màu sắc và tỷ lệ sống trên cá rô phi đỏ. Tương quan di truyền thuận và thấp, khác zero (0) có ý nghĩa thống kê giữa khối lượng với tính trạng tỷ lệ sống cũng được tìm thấy trên cá tra qua 3 thế hệ chọn giống $(0,27$; Nguyen \& ctv., 2019) và thuận trung bình và khác zero $(0)$ có ý nghĩa thống kê giữa 2 tính trạng cũng được tìm thấy ở thế hệ chọn giống tôm sú thứ 4 (Nguyen \& ctv., 2020).

\subsection{Tương tác kiểu gen và môi trường $(\mathrm{G} \times \mathrm{E})$ các tính trạng nghiên cứu ở hai môi trường nuôi khác nhau}

Bảng 4 trình bày tương quan di truyền cùng tính trạng được xem như là 2 tính trạng ở 2 môi trường nuôi khác nhau. Nhìn chung, tương quan di truyền tính trạng tăng trưởng (khối lượng, chiều dài tổng, chiều dài chuẩn) giữa 2 môi trường ao nuôi nước ngọt và ao nuôi nước lợ mặn đều là tương quan thuận và ở mức cao $(0,63-0,80)$ và khác 1 có ý nghĩa thống kê $(P<0,05)$, ngoại trừ giá trị này cho khối lượng thu hoạch. Theo Robertson (1959) giá trị tương quan di truyền $\mathrm{r}_{\mathrm{g}}$ ở mức 0,8 là cột mốc để đánh giá $\mathrm{G} \times \mathrm{E}$ có hoặc không hiện diện. Theo đó, khi tương quan di truyền lớn hơn 0,8 thì $\mathrm{GxE}$ là không tồn tại. Trong khi tương quan ở mức nhỏ hơn 0,8 và lớn hơn 0,65 thì tương tác $\mathrm{G} \times \mathrm{E}$ được xem là có xuất hiện, nhưng không có ý nghĩa về mặt sinh học (Robertson, 1959). Tuy nhiên, về mặt toán học thì chỉ hoàn toàn không có tương tác khi $\mathrm{r}_{\mathrm{g}}$ là 1 , nếu $\mathrm{r}_{\mathrm{g}}$ nhỏ hơn 1 thì luôn có tương tác. Giá trị $\mathrm{r}_{\mathrm{g}}$ thuận và cao cho tính trạng khối lượng $\left(\mathrm{r}_{\mathrm{g}}\right.$ $=0,63$ ), cho thấy có $\mathrm{GxE}$ ở mức thấp. Do đó, khi áp dụng chọn lọc đối với tính trạng khối lượng lúc thu hoạch cần xem xét chọn những cá thể thuộc các gia đình tăng trưởng tốt ở cả môi trường nước ngọt và lợ mặn, vì xu hướng nuôi cá rô phi đỏ trong nước lợ mặn ngày càng tăng. Từ ba giá trị tương quan trên ta có thể thấy rằng, các số liệu ước tính cho các tính trạng tăng trưởng trong ao nuôi nước ngọt có thể sử dụng để đánh giá và chọn lọc cho các tính trạng tăng trưởng trong ao nuôi nước lợ mặn và ngược lại. Kết quả tương quan di truyền trong nghiên cứu này phù hợp với cùng quần thể chọn giống ở thế hệ G1, tính trạng khối lượng giữa hai môi trường nuôi là 0,67 cho 
thấy có $\mathrm{G}$ x E thấp cho tính trạng khối lượng thu hoạch giữa cá nuôi trong nước ngọt và lợ mặn (Trinh \& ctv., 2013) nhưng hầu như không tồn tại $\mathrm{G} x \mathrm{E}$ ở $\mathrm{G} 2\left(\mathrm{r}_{\mathrm{g}}=0,63\right.$; Trinh và ctv., 2016). Ở cá rô phi đỏ, tương quan di truyền giữa tăng trưởng trong ao và lồng nuôi nước ngọt rất cao $(0,92 \pm 0,06)$, trong khi đó giữa ao nước ngọt và bề nước lợ thấp $(0,33 \pm 0,14)$ (Thodesen \& ctv., 2013). Một kết quả tương tự khi nuôi cá rô phi đỏ trong môi trường nước ngọt nhưng mô hình nuôi khác nhau là ao và lồng, Nguyen \& ctv. (2017) đã báo cáo tương quan di truyền các tính trạng là tương quan thuận và cao $\left(\mathrm{r}_{\mathrm{g}}=0,90\right)$.

Bảng 4. Tương quan di truyền cùng tính trạng được xem như là 2 tính trạng ở 2 môi trường nuôi khác nhau

\begin{tabular}{cc}
\hline Chỉ tiêu tăng trưởng & $\begin{array}{c}\text { Tương quan di } \\
\text { truyền }\left(\mathrm{r}_{\mathrm{g}} \pm \mathrm{SE}\right)\end{array}$ \\
\hline Khối lượng $(\mathrm{g})$ & $0,63 \pm 0,17$ \\
Chiều dài tồng $(\mathrm{cm})$ & $0,80 \pm 0,15$ \\
Chiều dài chuẩn $(\mathrm{cm})$ & $0,74 \pm 0,17$ \\
Tỷ lệ sống & $-0,17 \pm 0,40$ \\
Màu sắc & $0,77 \pm 0,10$ \\
\hline
\end{tabular}

Tương tự đối với tính trạng màu sắc, tương quan di truyền $\left(\mathrm{r}_{\mathrm{g}}\right)$ thuận và cao được ước tính giữa ao nuôi nước ngọt và ao nuôi nước lợ mặn $(0,77 \pm 0,10)$. Kết quả này cho thấy có $\mathrm{G} \times \mathrm{E}$ thấp giữa hai môi trường. Do đó, khi áp dụng chọn lọc cũng cần lưu ý như cho tính trạng khối lượng thu hoạch. Đối với tỷ lệ sống, tương quan di truyền nghịch và thấp $(-0,17)$, sai số chuẩn cao và cho thấy có $\mathrm{G} x \mathrm{E}$. Kết quả này chỉ ra rằng các số liệu ước tính cho tỷ lệ sống trong ao nuôi nước ngọt không thể sử dụng để đánh giá và chọn lọc cho tỷ lệ sống trong ao nuôi nước lợ mặn. Do đó, đối với tính trạng tỷ lệ sống, cần lưu ý nếu muốn chọn lọc nâng cao tính trạng ở 2 môi trường cần có quần đàn chọn giống riêng hoặc có thể sử dụng chỉ số chọn giống (selection index) để chọn lọc, nhưng khi đó hiệu quả mang lại cho từng môi trường sẽ thấp (Gjerde, 2005). Theo Sae-Lim \& ctv. (2016) khi tổng quan G x E tính trạng tăng trưởng và tỷ lệ sống ở một số đối tượng thuỷ sản trên thế giới cho thấy tương quan di truyền $\left(\mathrm{r}_{\mathrm{g}}\right)$ nằm trong khoảng $0,54-0,72$. Từ đây, nhóm tác giả cũng lưu ý xem xét chọn lọc đình tính trạng quan tâm cho cá thể hay gia đình biểu hiện tốt cả 2 môi trường và có thể hình thành 2 quần thể chọn giống khác nhau cho 2 môi trường.

Đối với quần thể chọn giống rô phi đỏ G5 trong nghiên cứu này có tương quan di truyền cũng như $\mathrm{G} \times \mathrm{E}$ khi ước tính với sai số (SE) lớn. Trong khi đó, chương trình chọn giống cũng đã có số liệu đánh giá tính trạng ở môi trường nước ngọt qua 5 thế hệ và lợ mặn 3 thế hệ (G1, G2, G5), nếu chúng ta gộp số liệu nhiều thế hệ và xử lý chung thì có thể ước tính các thông số di truyền chính xác hơn với sai số nhỏ hơn.

\section{Kết Luận}

Hệ số di truyền tính trạng khối lượng, tỷ lệ sống và màu sắc lúc thu hoạch cá rô phi đỏ chọn giống thế hệ thứ 5 ở mức trung bình đến cao, tiềm năng cho chọn lọc tiếp theo mang lại hiệu quả ở mức trung bình đến cao. Tương quan di truyền giữa 3 tính trạng này khác zero không có ý nghĩa thống kê, nên nếu chọn lọc nâng cao khối lượng hay 1 trong 2 tính trạng kia thì không làm thay đổi lớn cải thiện di truyền 2 tính trạng còn lại. Tương tác kiểu gen và môi trường cho tính trạng khối lượng và màu sắc tồn tại ở mức thấp giữa 2 môi trường nuôi nước ngọt và lợ mặn, nên việc chọn giống vẫn có thể thực hiện tạo quần thể có đặc tính tốt cho từng tính trạng. Đối với tính trạng tỷ lệ sống do có tương tác kiểu gen và môi trường nên cần chú ý khi tính toán đến chọn lọc đồng thời cho 2 môi trường hay thành lập 2 quần thể chọn giống theo tính trạng này.

\section{Lời Cam Đoan}

Chúng tôi xin tuyên bố không có mâu thuẫn nào giữa các tác giả và đồng tác giả của bài báo.

\section{Lời Cảm Ơn}

Nghiên cứu được thực hiện trong khuôn khổ dự án 'Hoàn thiện công nghệ chọn tạo giống rô phi đỏ (Oreochromis spp.) tăng trưởng nhanh, 2017-2019' thuộc chương trình Công nghệ Sinh học Nông nghiệp và Thuỷ sản - Bộ Nông Nghiệp và Phát triển Nông thôn. Chân thành cám ơn các anh chị thuộc Viện Nghiên cứu Nuôi trồng Thủy sản II đã tham gia một số công việc liên quan cùng nhóm nghiên.

\section{Tài Liệu Tham Khảo (References)}

Bentsen, H. B., Gjerde, B., Nguyen, N. H., Rye, M., Ponzoni, R. W., Palada de Vera, M. S., Bolivar, H. L., Velasco, R. R., Danting, J. C., Dionisio, E. E., Longalong, F. M., Reyes, R. A., Abella, T. A., Tayamen, M. M., \& Eknath, A. E. (2012). Genetic improvement of 
farmed tilapias: Genetic parameters for body weight at harvest in Nile tilapia (Oreochromis niloticus) during five generations of testing in multiple environments. Aquaculture 338-341, 56-65.

Gilmour, A., Gogel, B., Cullis, B., Welham, S., \& Thompson, R. (2015). ASReml user guide release 4.1 structural specifcation. Hemel Hempstead, England: VSN International.

Gjerde, B. (2005). Design of breeding programs. In Gjedrem, T. (Ed.). Selection and breeding programs in aquaculture (73-195). Heidelberg, Netherlands: Springer.

Nguyen, H. N., Hamzah, A., \& Thoa, N. P. (2017). Effects of genotype by environment interaction on genetic gain and genetic parameter estimates in red tilapia (Oreochromis spp.). Frontiers in Genetics 8, 82.

Nguyen, H. V. (2021). "Mighty eagerness" in the version for the lunar new year. Vietnam Fisheries Magazine, $3 \& 4,86-87$.

Nguyen, T. V., Nguyen, V. S., Tran, H. P., Nguyen, T. V., \& Nguyen, N. H. (2019). Genetic evaluation of a 15year selection program for high growth in striped catfish Pangasianodon hypophthalmus. Aquaculture 509, 221-226.

Nguyen, V. S., Nguyen, T. L., Nguyen, V. H., Tran, V. N., Nguyen, T. V., \& Nguyen, H. N. (2020). Genotype by environment interaction for survival and harvest body weight between recirculating tank system and pond culture in Penaeus monodon. Aquaculture 525, 735278.

Robertson, A. (1959). The sampling variance of the genetic correlation coefficient. Biometrics 15(3), 469-85.

Sae-Lim, P., Gjerde, B., Nielsen, H. M., Mulder, H., \& Kause, A. (2016). A review of genotype-byenvironment interaction and micro-environmental sensitivity in aquaculture species. Aquaculrue 8, 369-393.
Thodesen, J., Rye, M., Wang, Y. X., Li, S. J., Bentsen, H. B., \& Yazdi, M. H., \& Gjedrem, T. (2013). Genetic improvement of tilapias in China: genetic parameters and selection responses in growth, survival and external color traits of red tilapia (Oreochromis spp.) after four generations of multi-trait selection. Aquaculture 416, 354-366.

Tran, D. T., \& Dang, H. L. (2005). Genetic basis and selective breeding in fish. Nha Trang, Vietnam: Nha Trang Fisheries University.

Trinh, Q. T., Nguyen, V.S., Tran, H. P., Nguyen, C. M., Pham, D. K., Lao, T. T., \& Le, T. D. (2013). Genetic papameters of growth rate on red tilapia (Oreochoromis spp.). Mekong Journal of Fisheries 02, 2429 .

Trinh, Q. T., Phạm, D. K., Le, T. D., Nguyen, T. T., Nguyen, T. V., \& Nguyen, T. D. (2017). Red tilapia seed improvement through 3 generations of selection. Mekong Journal of Fisheries 10, 66-75.

Trinh, Q. T., Phạm, D. K., Le, T. D., Nguyen, T. T., Nguyen, T. V., Nguyen, T. D., \& Tran, H. P. (2016). Final report of project 'application of molecular and quantitative genetics for selective breeding of red tilapia (Oreochromis spp.) for improving growth rate'. Ho Chi Minh City, Vietnam: Research Institute of Aquaculture 2.

WFC (World Fish Center). (2004). GIFT technology manual: An aid to tilapia selective breeding. Penang, Malaysia. Retrieved January 21, 2021, from https://www.worldfishcenter.org/content/gifttechnology-manual-aid-tilapia-selective-breeding. 